\title{
Sintering and Wear Behavior of a FeCrCB Hardfacing Alloy Applied by Tape Casting: A Study of Cooling Rate Effect
}

\author{
Fernando Valenzuela de la Rosa, Roal Torres Sánchez, José T. Holguín-Momaca, \\ Carlos Domínguez Ríos*, Alfredo Aguilar Elguezabal
}

Centro de Investigación en Materiales Avanzados S.C., Laboratorio Nacional de Nanotecnología, Chihuahua, México

Email: *carlos.dominguez@cimav.edu.mx

How to cite this paper: de la Rosa, F.V., Sánchez, R.T., Holguín-Momaca, J.T., Ríos, C.D. and Elguezabal, A.A. (2020) Sintering and Wear Behavior of a FeCrCB Hardfacing Alloy Applied by Tape Casting: A Study of Cooling Rate Effect. Journal of Minerals and Materials Characterization and Engineering, 8, 393-406.

https://doi.org/10.4236/jmmce.2020.85025

Received: July 30, 2020

Accepted: September 7, 2020

Published: September 10, 2020

Copyright (C 2020 by author(s) and Scientific Research Publishing Inc. This work is licensed under the Creative Commons Attribution International License (CC BY 4.0)

http://creativecommons.org/licenses/by/4.0/

\begin{abstract}
This study presents a simple process to deposit a hardfacing coating on a steel substrate, based on the sintering of metallic powder applied by tape casting (by a slurry of metallic powder suspension onto a steel substrate) thus avoiding the use of traditional welding processes and their variants. The effect of the cooling of hardfacing after the sintering process, by air at room temperature or by quenching in water, was studied. This new method ensures a good metallurgical bonding between the substrate steel and the hardfacing layer and shows mechanical property improvement on coated pieces, similar to those exhibited by hardfacing coatings produced by several kinds of welding processes. The characterization of the hardfacing coatings was made by X-ray diffraction, optical microscopy, scanning electron microscopy, microhardness and wear resistance according to the ASTM G65 standard. The characterization results show that the presented faces are: $\mathrm{M}_{7} \mathrm{C}_{3}, \mathrm{M}_{3} \mathrm{C}, \mathrm{MC}, \mathrm{M}_{2} \mathrm{~B}$ and $\mathrm{M}_{23} \mathrm{~B}_{6}$; there are three different phases in the micrograph glass phase, eutectic phase and hard phase with a volumetric fraction of $0.14,0.20$ and 0.66 , respectively, for the air cooled and $0.15,0.16$ and 0.69 when quenched in water. The average microhardness value for the parts cooled in air was 832.5 $\mathrm{HV}$ and for that cooled in water was $958.9 \mathrm{HV}$, and the wear resistance was a mass loss of 0.219 and $0.128 \mathrm{~g}$ for parts cooled in air and water, respectively. These results show that the hardfacing coating could have twice the hardness and wear resistance than that observed for the boron steel used as a substrate.
\end{abstract}

\section{Keywords}

Hardfacing, Sintering, Cooling Rate, Wear Resistance 


\section{Introduction}

For primary and secondary industries, abrasive wear is one of their biggest problems. Abrasive wear occurs when a particle impacts a piece with some strength, and the particle hardness is higher than hardness of the piece [1]. Many pieces used in primary and secondary industries are used under these conditions on a daily basis. Historically, different solutions have been developed to deal with this issue, such as the use of heat treatments or changing the material composition [2]. The use of hardfacing coatings began in 1896 [3]. A hardfacing coating is defined as the deposition of a durable surface coating on a base material (substrate) in order to increase their properties, like wear resistance by impact, abrasion, erosion, or pitting and corrosion or any combination of these [1]. Hardfacing coatings began their implementation using the traditional welding processes, such as flux-cored arc welding, gas metal arc welding, gas tungsten arc welding, plasma arc welding, shielded metal arc welding, submerged arc welding and oxy-fuel arc welding (respectively, FCAW, GMAW, GTAW, PAW, SMAW, SAW and OFW). In recent years, the newest welding processes have evolved, such as electroslag welding, laser beam welding, electron beam welding, friction stir welding and furnace brazing (respectively, ESW, LBW, EBW, FSW and $\mathrm{FB}$ ) [4]. Besides welding processes, the use of thermal spray methods to create hardfacing coatings began in 1911. These methods consist in the projection of molten metals atomized by a stream of high-pressure gas and propelled onto the surface to coat [5].

This work presents a method to apply a hardfacing coating by a simple process, where the coating is prepared by mixing metallic powder of the hardfacing alloy with water and flux to form slurry. The slurry is then applied onto the substrate by a simple technique like tape casting (doctor blading), and after drying the piece is thermally treated for sintering of the coating. Thereafter, final properties of coated pieces are defined by cooling rate.

Through the method of applying a hardfacing coating by the study processes of this research paper, the significant problem of the heat affected zone (HAZ) that is caused in traditional welding processes is avoided. Another important characteristic of this method is that it allows the slurry to be applied by cascade, immersion or spray methods, by controlling the rheological characteristics of the slurry.

\section{Material and Methods}

The metal powders were manufactured by Metallied Powder Solutions S.A. in Guipuzcoa, Spain. The composition of the metallic powder was prepared according to the composition previously reported by Revankar [6], see Table 1 .

Table 1. Chemical composition of powder of the hardfacing alloy.

\begin{tabular}{rccccccc}
\hline Element & B & C & Cr & Mn & Ni & $\mathrm{Si}$ & Fe \\
\hline Weight \% & 3.29 & 2.18 & 14.44 & 0.31 & 5.72 & 3.09 & Balance \\
\hline
\end{tabular}


The boron steel that was used as the substrate was provided by the Mexican company Altos Hornos de México S.A. The chemical composition of the substrate steel is shown in Table 2.

The slurry consists of metallic powder ( $89 \%$ of weight), flux (2\%) and water (9\%), it and was vigorously stirred for two minutes or until homogeneity of the suspension was reached. The boron steel substrate (see Table 1) was cut into pieces of $25.4 \times 76.2 \times 6.35 \mathrm{~mm}$. The pieces were sandblasted to remove the oxide, grease and dirt layer of the surface. After sandblasting, pieces were put into an ultrasonic bath with acetone for 5 minutes to remove any remaining grease.

The homogeneous slurry was applied to the substrate by tape casting technique, with the aid of an instrument used for a glaze laying test, as shown in Figure 1. This device allows the application of an even thickness of $2 \mathrm{~mm}$ in a single step. Once the slurry was applied onto the substrate, samples were put in an oven at $200^{\circ} \mathrm{C}$ for 80 minutes. In order to determine the sintering temperature, $5 \mathrm{mg}$ of slurry were put into a cubic mold to make a dilatometric test. This test was carried out in an Expert System Solutions dilatometer, model Misura ODHT 1400-80. The test parameters were maximum temperature of $1180^{\circ} \mathrm{C}$ and heating rate of $30^{\circ} \mathrm{C} / \mathrm{min}$, and the results are shown in Figure 2. Dried samples were then put into a furnace for the sintering process, which was performed using argon gas to maintain an inert atmosphere. The temperature of sintering was $1140^{\circ} \mathrm{C}$, which was determined by dilatometry. The sintering temperature of $1140^{\circ} \mathrm{C}$ was determined from the dilatometry test because, as it is a graphic representation of the expansion/contraction vs temperature, when there is an abrupt change in slope in the graph of expansion vs. temperature, that is, a contraction of the material begins, at that point it is indicative of the higher sintering rate due to the activation of all the diffusion mechanisms of the chemical species that make up the material under study. To reach the sintering temperature, the heating rate was $23^{\circ} \mathrm{C} / \mathrm{min}$, and this temperature was maintained for ten minutes. Thereafter, the samples were removed from the oven and cooled in air or water at room temperature.

$\mathrm{X}$-ray analysis was performed on the surface of the coating to ensure that only the hardfacing coating was exposed, without interference from the substrate. The samples of size $25.4 \times 25.4 \times 6.35 \mathrm{~mm}$ were put in a Panalytical X'pert Plus $\mathrm{X}$-ray diffractometer, and analyses were made under these conditions: step size of $0.3^{\circ}$, dwell time of $10 \mathrm{~s}$, range of $20^{\circ}-80^{\circ}$, with the method of $\theta-2 \theta$. The samples for the optical microscopy and scanning electron microscopy were viewed by cross-section. The cross-section of the hardfacing coatings were analyzed by EDS maps using a Hitachi model SU3500 SEM. The microhardness test was made in a Vickers microhardness tester, Future Tech $\mathrm{MH}-00$, using a load of $500 \mathrm{~g}$ and a dwell time of $12 \mathrm{~s}$. For the wear resistance test, the ASTM G65 standard suggests three samples of size $25.4 \times 76.2 \times 6.35 \mathrm{~mm}$ and the use of Procedure B [7]. 
Table 2. Chemical composition of the steel substrate.

\begin{tabular}{cccccccccc}
\hline Element & $\mathrm{C}$ & $\mathrm{Si}$ & $\mathrm{Mn}$ & $\mathrm{P}$ & $\mathrm{S}$ & $\mathrm{Cr}$ & $\mathrm{Al}$ & $\mathrm{B}$ & $\mathrm{Fe}$ \\
\hline Weight \% & 0.3000 & 0.2100 & 1.1400 & 0.0155 & 0.0060 & 0.1950 & 0.0465 & 0.0018 & Balance \\
\hline
\end{tabular}

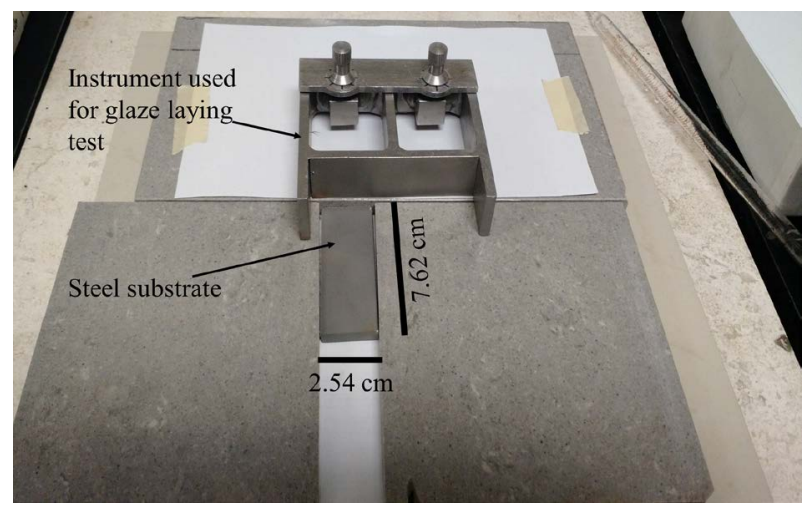

Figure 1. Device for the application of metallic powder slurry on the substrate, by tape casting technique.

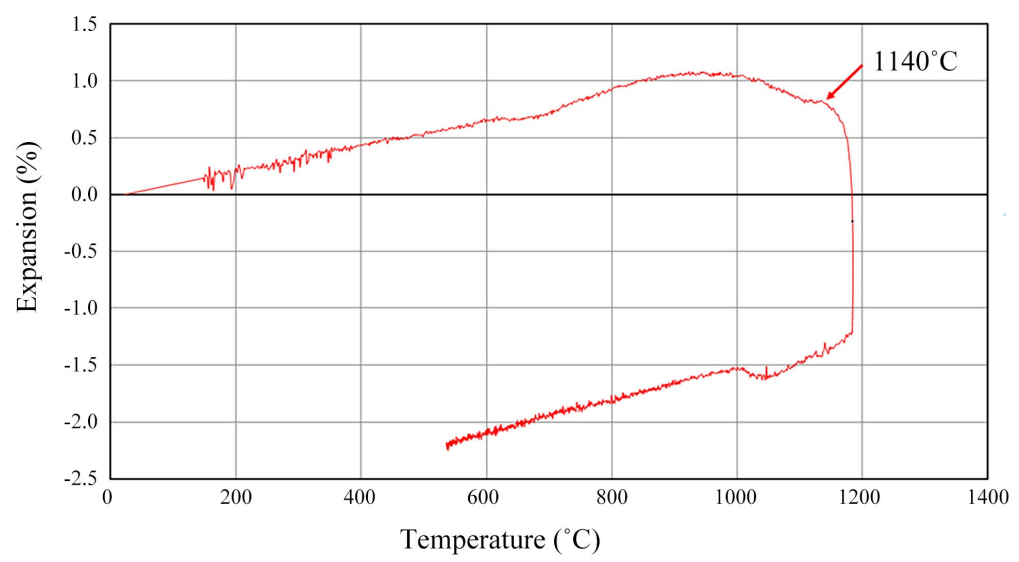

Figure 2. Metallic powder dilatometry.

\section{Results and Discussion}

\subsection{X-Ray Diffraction}

The X-ray diffraction patterns of the metallic powder as received and the hardfacing coatings cooled in air and water are shown in Figure 3. The phases presented in the metallic powder as received are solid solutions: $\mathrm{CrFeSi}$ and $\mathrm{FeCr}$, carbide phases: $\mathrm{Cr}_{7} \mathrm{C}_{3}$ and $\mathrm{Fe}_{3} \mathrm{C}$ and boride phases: $\mathrm{Fe}_{2} \mathrm{~B}$ and $\mathrm{Mn}_{2} \mathrm{~B}$.

After the sintering process, the microstructure evolves, dissolving the solid solutions, leaving only $\mathrm{Fe}_{0.87} \mathrm{Cr}_{1.13}$ and increasing the amount of carbides, such as $\mathrm{Fe}_{3} \mathrm{C}, \mathrm{Fe}_{7} \mathrm{C}_{3}$ and $\mathrm{Mn}_{7} \mathrm{C}_{3}$, and the number of borides, such as $\mathrm{Mn}_{2} \mathrm{~B}, \mathrm{CrB}_{2}, \mathrm{Fe}_{2} \mathrm{~B}$ and $\mathrm{Fe}_{3} \mathrm{~B}$. These phases have been reported as $\mathrm{M}_{7} \mathrm{C}_{3}, \mathrm{M}_{23} \mathrm{C}_{6}$ and $\mathrm{MB}_{2}$, where $\mathrm{M}$ could be Fe, $\mathrm{Cr}$ and $\mathrm{Mn}$ or any combination of them [8] [9] [10] [11] [12]. The chemical composition was obtained from the JCPDS database for each of the phases identified in the X-ray diffraction patterns. 


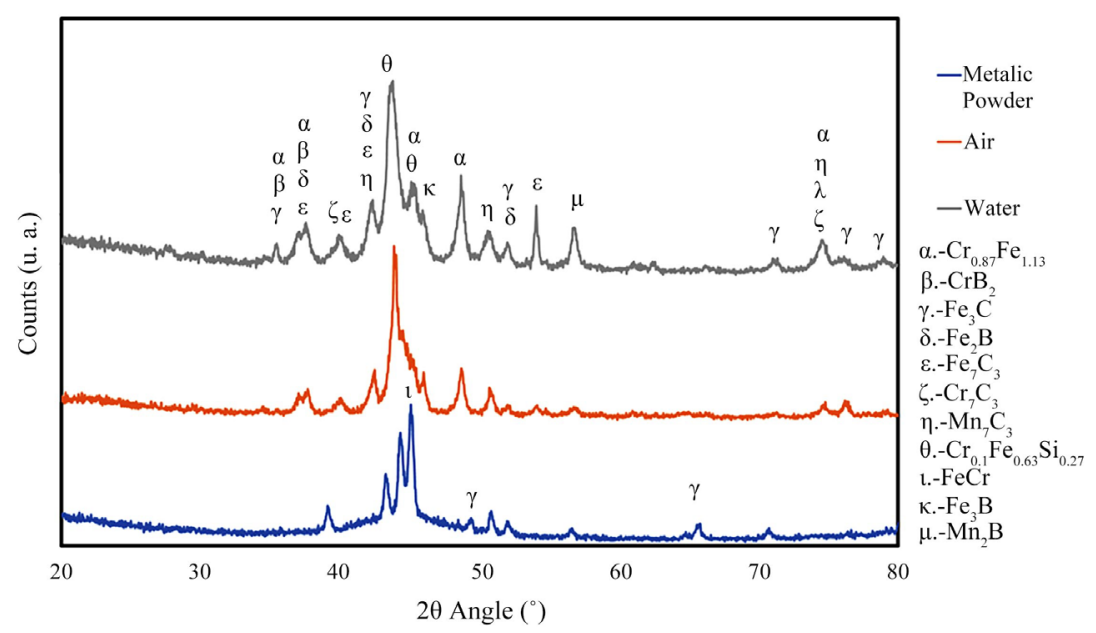

Figure 3. X-ray diffraction patterns of the metallic powder as received and the hardfacing coatings after sintering and air or water cooling cooled in air or water.

\subsection{Optical Microscopy}

Figure 4 shows micrographs of the samples cooled in (a) air and (b) water. From observation of these images, it seems that the sample cooled in air is formed by hard phases of the type $\mathrm{M}_{7} \mathrm{C}_{3}, \mathrm{M}_{3} \mathrm{C}, \mathrm{MC}, \mathrm{M}_{2} \mathrm{~B}$ and $\mathrm{M}_{23} \mathrm{~B}_{6}$, surrounded by a laminar eutectic, which is formed by the hard phases of $\mathrm{M}_{7} \mathrm{C}_{3}, \mathrm{M}_{3} \mathrm{C}, \mathrm{MC}, \mathrm{M}_{2} \mathrm{~B}$ and $\mathrm{M}_{23} \mathrm{~B}_{6}$, with a solid solution of $\mathrm{Cr}_{0.87} \mathrm{Fe}_{1.13}$. This microstructure is similar to that obtained by filler wire welding of a hardfacing alloy [8]. The samples cooled in water had a microstructure of hard phases $M_{7} C_{3}, M_{3} C, M C, M_{2} B$ and $M_{23} B_{6}$, surrounded by a eutectic skeleton which was made by the same type of hard phases, only smaller. The darkest phase is a glass phase produced by the flux.

Table 3 presents the volume fractions of the three principal phases, glass, eutectic and hard, for the two cooling rates. As can be seen, the volume fraction of glass phase is almost the same for both conditions: 0.14 for the sample cooled in air and 0.15 for the sample cooled in water. This confirms that this phase is produced by the flux, since both conditions have the same amount of flux. Otherwise, the amount of eutectic phase in the sample cooled in water $(0.16)$ is lower than the amount of eutectic phase for the sample cooled in air (0.20), which can be explained by the reduction of time available for atoms to diffuse and conform the eutectic phase under water cooling, since a drastic lowering of temperature occurs. As can be seen in the micrographs, the size of the hard phase in the sample cooled in air is $50-150 \mu \mathrm{m}$, while in the sample cooled in water the size of the hard phase is up to a maximum of $50 \mu \mathrm{m}$.

\subsection{Scanning Electron Microscopy}

In order to study the interphase between the substrate and the coating, samples were analyzed by SEM. The EDS maps show that there exists diffusion from the elements of the hardfacing coating into the steel substrate, chromium being the element with a higher diffusion. These maps are presented in Figure 5 and Figure 6, for samples cooled in air and water, respectively. 
Table 3. Volume fraction of phases on hardfacing coating for samples cooled in air or water.

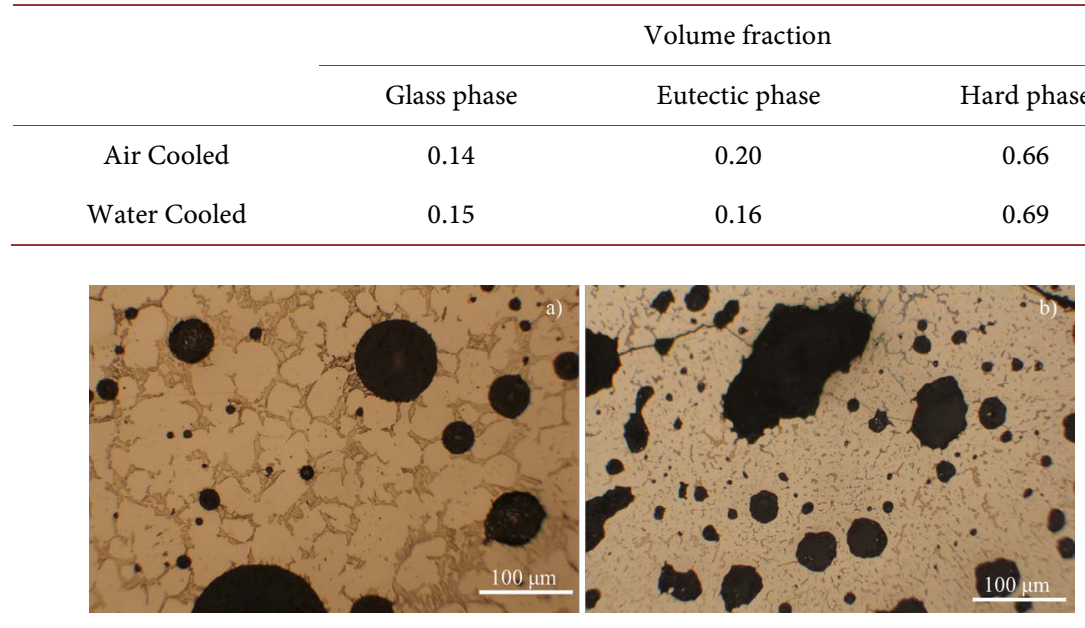

Figure 4. Cross-sectional micrograph of the hardfacing coating, cooled in (a) air and (b) water after sintering treatment.

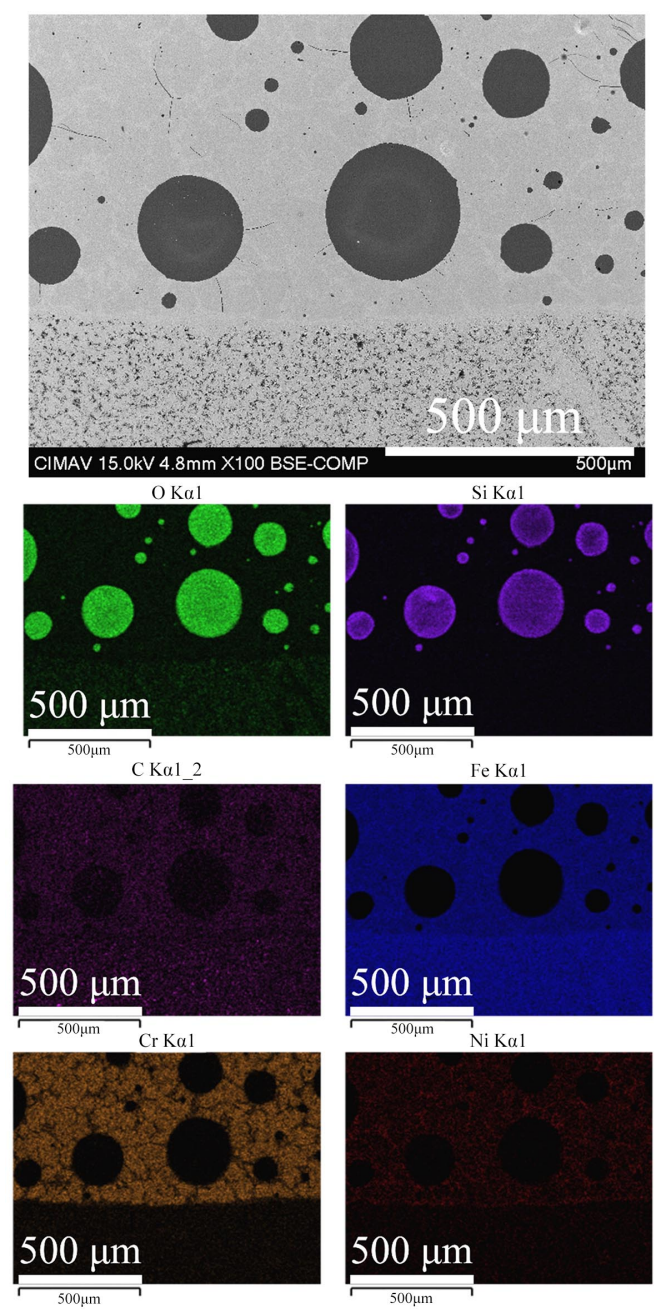

Figure 5. EDS maps of the hardfacing coating cooled in air after sintering. 


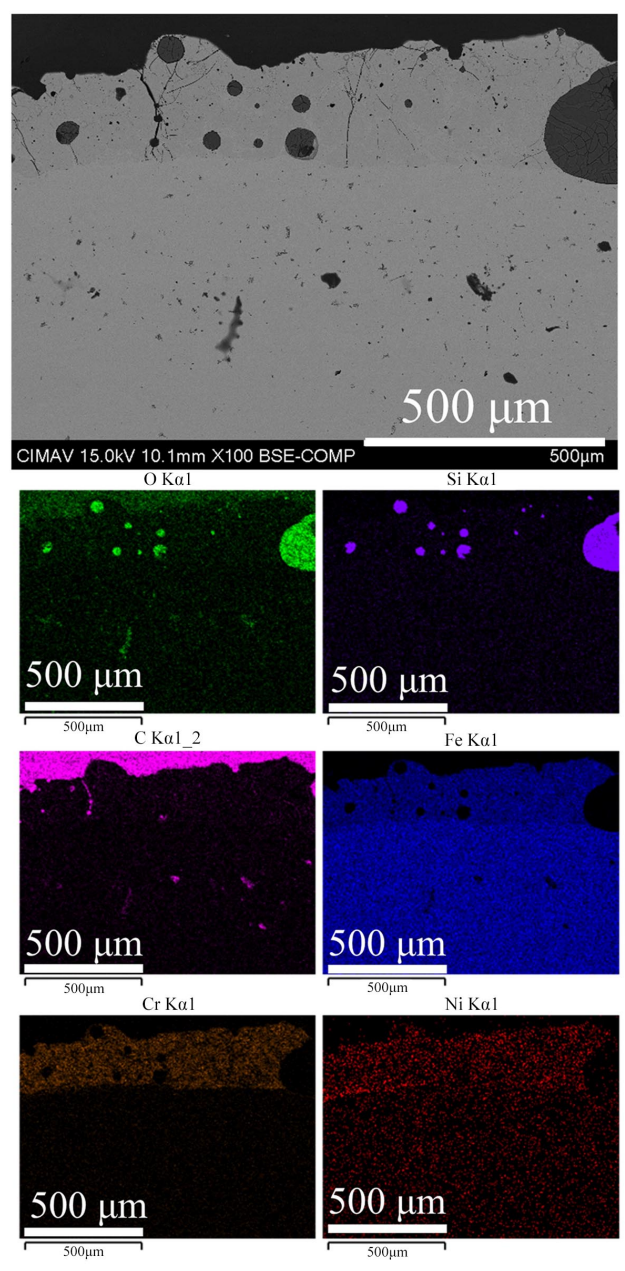

Figure 6. EDS maps of the hardfacing coating cooled in water after sintering.

Figure 7(a) and Figure 7(b) show the micrographs of the interphase between the hardfacing coating and the steel substrate, and none of them show separation between the hardfacing coating and the steel substrate. In Figure 7(b) for the sample cooled in water, we can see the presence of cracks in the hardfacing coating, which we assume are produced by the higher cooling rate, because there are no such cracks in Figure 7(a) for the sample cooled in air. Figures 8(a)-(c) show micrographs of the sample cooled in air. In this condition, we can see the presence of hard phases surrounded by a laminar eutectic, such as the ones described by [1] [8] [13], where $\alpha$ is a hard phase, $\beta$ is a laminar eutectic phase and $\gamma$ is the glass phase.

Figures $8(\mathrm{~d})-(\mathrm{f})$ show micrographs of the sample cooled in water. In this condition, we can see the microstructure of metastable hard phases such as $\delta$ surrounded by the phase $\varepsilon$ that is a eutectic skeleton phase and also the glass phase $\gamma$. As can be observed in the microphotographs, the microstructure of the sample cooled in water is finer than the sample cooled in air, which can cause an increase in microhardness, and better performance in the wear resistance test can be expected. 

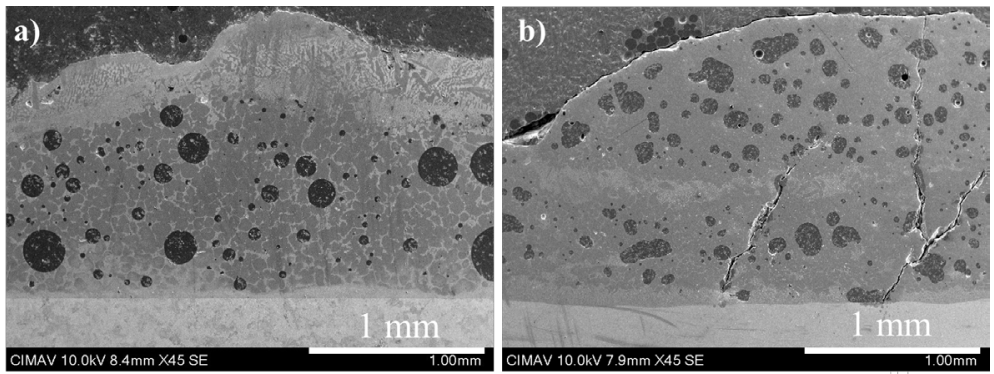

Figure 7. Cross-sectional micrograph of the hardfacing coating after sintering and cooled in (a) air and (b) water.
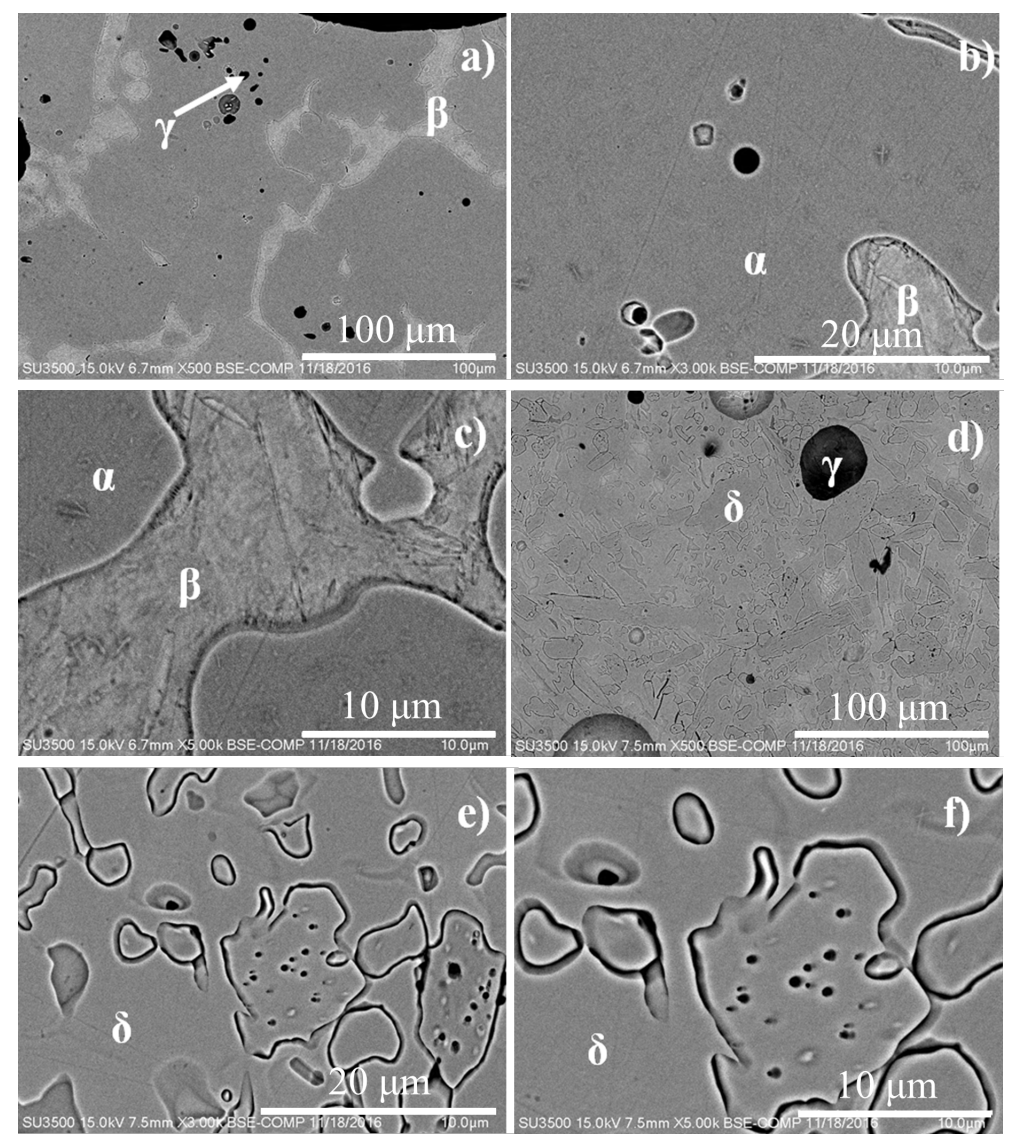

Figure 8. Cross-sectional micrograph of the hardfacing coating, cooled in air (a), (b) and (c); and water (d), (e) and (f).

\subsection{Microhardness}

The microhardness test was made in a Vickers microhardness tester Future Tech MH-00, using a load of $500 \mathrm{~g}$ and a dwell time of $12 \mathrm{~s}$. For each sample, ten measurements were made in a random distribution on the surface of the hardfacing coating. The average microhardness for samples cooled in air was $832.5 \pm$ $52 \mathrm{HV}$ whereas $958.9 \pm 152 \mathrm{HV}$ was the average microhardness for samples cooled by water. These results are in accordance with those reported by several works [1] [2] [4] [8] [11] [13] for conventional welding techniques of hardfacing application and are even better than those reported by Lai et al. [14] where the 
hardfacing coating had more chromium and was also applied by a welding process. Besides these ten measurements made in random phases, another ten measurements were made specifically in hard phases, as well as ten measurements in the eutectic phase, using a load of $50 \mathrm{~g}$ and a dwell time of $10 \mathrm{~s}$. These results are shown in Table 4. As can be seen in the microhardness results, the composite substrate and hardfacing coating have a higher hardness when the samples were cooled in water from the final sintering temperature, and this is because there is no time for the alloy elements to diffuse. On the other hand, from the point of view of the present phases, the eutectic phase in the samples cooled with water is greater due to the size and skeletal structure that is formed by the rapid cooling; while in the sample cooled in air, the laminar eutectic is larger. Another important aspect that can be seen in the microhardness is the higher hardness of the substrate in the sample cooled in water compared to the sample cooled in air.

\subsection{Wear Resistance}

The wear resistance test was made in equipment as described in the ASTM G65 standard, using Procedure B. Table 5 shows the conditions of analysis. This test was chosen to simulate a low-stress abrasion condition, which typically occurs in tillage tools for soil preparation in normal working conditions [15]. Three tests were made for each cooling condition as is recommended by the standard.

Table 6 shows the results of microhardness of the AFS 50/70 Test Sand provided by Ottawa Silica Co. The $\mathrm{Ha} / \mathrm{Hc}$ rate is calculated from $\mathrm{Ha}$ (hardness of the abrasive) and Hc (hardness of each coating). The wear rate is calculated according to Equation (1), and the specific wear rate is calculated according to Equation (2). The values of volume loss, wear rate and specific wear rate are in accordance with those reported by [15] [16], for samples cooled in water. For hardness ratio $\mathrm{Ha} / \mathrm{Hc}$ in the range 0.7 - 1.1, a good performance of hardfacing is considered for wear resistance whereas for ratios in the range $1.3-1.7$, maximum wear is possible [17] [18] [19] [20].

Table 4. Microhardness of the eutectic and hard phases and the substrate.

\begin{tabular}{cccc}
\hline & \multicolumn{3}{c}{ Microhardness (HV) } \\
\cline { 2 - 3 } Sample & \multicolumn{2}{c}{ Phase } & Substrate \\
\cline { 2 - 4 } & Eutectic & Hard & 279.6 \\
\cline { 2 - 3 } Air Cooled & 445.7 & 1137.8 & 677.7 \\
\hline
\end{tabular}

Table 5. Test conditions for Procedure B of the ASTM G65 standard.

\begin{tabular}{cccccc}
\hline $\begin{array}{c}\text { Specific } \\
\text { Procedure }\end{array}$ & $\begin{array}{c}\text { Force against } \\
\text { Specimen (N) }\end{array}$ & $\begin{array}{c}\text { Wheel } \\
\text { Revolutions }\end{array}$ & $\begin{array}{c}\text { Lineal } \\
\text { Distance }(\mathrm{m})\end{array}$ & $\begin{array}{c}\text { Speed (rpm) } \\
\text { B }\end{array}$ 130 $^{2000}$ & $\begin{array}{c}\text { Sand Flow } \\
\left(\mathrm{gmin}^{-1}\right)\end{array}$ \\
\hline
\end{tabular}


Table 6. Specific wear rate of hardfacing coating for hardfacing samples cooled in air and samples cooled in water.

\begin{tabular}{cccccc}
\hline & $\begin{array}{c}\text { Microhardness } \\
\text { of Sand (HV) }\end{array}$ & $\mathrm{Ha} / \mathrm{Hc}$ & $\begin{array}{c}\text { Volume Loss } \\
\left(\mathrm{mm}^{3}\right)\end{array}$ & $\begin{array}{c}\text { Wear Rate } \\
\left(\mathrm{mm}^{3} \mathrm{~m}^{-1}\right)\end{array}$ & $\begin{array}{c}\text { Specific Wear Rate } \\
\left(1 \times 10^{-14} \mathrm{~mm}^{3} \mathrm{~m}^{-2} \mathrm{~N}^{-1}\right)\end{array}$ \\
\hline Air Cooled & 1304.96 & 1.57 & 28.93 & 0.02 & 15.49 \\
Water Cooled & & 1.36 & 16.91 & 0.01 & 9.06 \\
\hline
\end{tabular}

$$
\begin{gathered}
\text { wear rate }=\frac{\operatorname{volume} \operatorname{losss}\left(\mathrm{mm}^{3}\right)}{\text { sliding distance }(\mathrm{m})} \\
\text { specific wear rate }=\frac{\operatorname{volume} \operatorname{loss}\left(\mathrm{mm}^{3}\right)}{\text { sliding distance }(\mathrm{m}) * \text { force against specimen }(\mathrm{N})}
\end{gathered}
$$

The average volume loss was $28.9 \mathrm{~mm}^{3}$ for the samples cooled in air and 16.9 $\mathrm{mm}^{3}$ for the samples cooled in water. According to the results of the table, it can be seen that the $\mathrm{Ha} / \mathrm{Hc}$ performance for the air-cooled sample may show significant wear according to the aforementioned criterion, while for the sample cooled in water, the wear exhibited is less than for the sample cooled in air. We can even think that the wear of the sample cooled in water barely reaches the lower limit of the criterion where the greatest wear occurs. The sample that presents less loss of material is the one cooled in water, which indicates an increase in the wear resistance. At the same time, it can be seen that the wear rate decreases by half to twice, and the specific wear rate decreases by approximately $40 \%$. This behavior can be explained in terms of the microstructure obtained with the cooling methods, since while the microstructure of the sample cooled in water is finer and has a lower amount of eutectic, in the sample cooled in air the microstructure is coarser and presents a greater amount of eutectic.

Figure 9 shows micrographs of the worn-out surfaces of the samples cooled in (a) air and (b) water. It can be seen in Figure 9(a) that the worn-out surfaces present continuous lines, whereas in Figure 9(b) these lines are discontinuous. In both micrographs, it can be seen that there is a material displacement to the edges of the lines left by the sand particles, which is indicative of the wear mechanism of micro-ploughing. Also, the lines in Figure 9(a) are deeper than those in Figure 9(b), and this confirms the higher wear resistance of the samples cooled in water.

As can also be seen in Figure 9, there are several holes in the worn surfaces of both materials, which suggest that a three-body wear mechanism is present. In this kind of wear mechanism, the abrasive sand particles can roll between the rubber and sample surfaces, and the surface material is removed by subsequent indentations of the sharp corners of the abrasive particles. In this case, since the grain size is large, consequently the distance between the hard phases are larger for the air-cooled hardfacing coating, and thus the size of these holes is larger than the holes in the water-cooled hardfacing, where the holes are smaller but in higher quantity. Similar behavior was reported by Trevisol et al. [20], for a dual phase ferrite-martensite on a low alloy steel, were the effect of volume fraction of 
phases and particle size of abrasive was studied under wear treatment. Thus, micro-ploughing is the more relevant mechanism for wear if the air-cooled hardfacing, and the three-body mechanism has more importance for water-cooled hardfacing cooled [21]. The higher hardness of the water-cooled hardfacing probably produces a brittle material, and the lower hardness of the air-cooled hardfacing coating leads to wear by plastic deformation and then failure. Micro-ploughing and holes are the main wear mechanisms identified for these hardfacing materials, which are common mechanisms on steel-based materials [20] [22] [23] [24].

Figure 10 shows micrographs of the cross-section of the worn-out zone of hardfacing samples cooled in (a) air and (b) water. In the sample cooled in water, micro-cracks develop due to the high rate of cooling. However, these do not grow during the wear resistance test. Figure 10(a) shows how cracks appeared on the hardfacing cooled by air, and sample after wear resistance test shows that these cracks connected, which can explain the lower wear resistance of the sample cooled by air.

Figure 11 shows the specific wear rate and the microhardness for both cooling conditions, and, as can be seen, there is a correlation between microhardness and specific wear rate, which consists in the decrease of specific wear rate as microhardness increases.

The higher wear resistance of the samples cooled in water can also be explained in terms of microstructure, since more volume fraction of hard phases was found in the hardfacing sample cooled by water, which showed better performance. The skeleton eutectic implies a greater barrier for the dislocation displacement toward the material, and this reduces the plastic deformation.
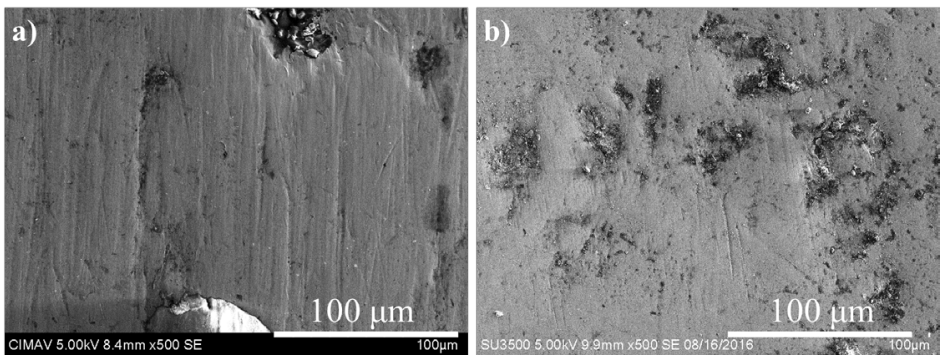

Figure 9. Surface micrograph of worn-out samples, cooled in (a) air and (b) water.

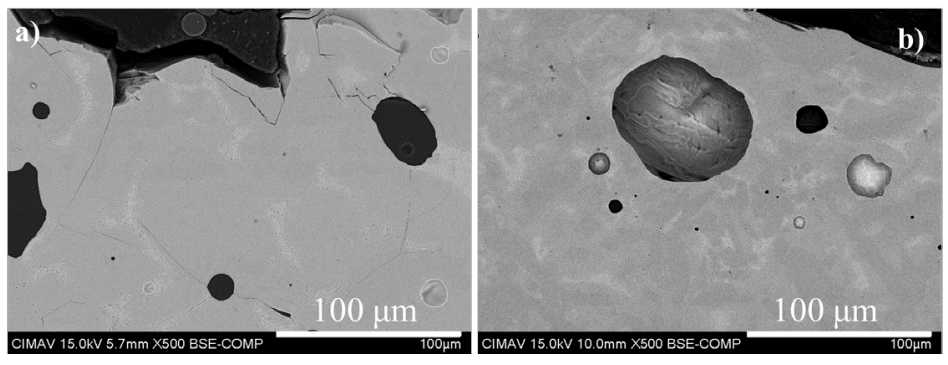

Figure 10. Cross-sectional micrograph of worn-out samples, cooled in (a) air and (b) water. 


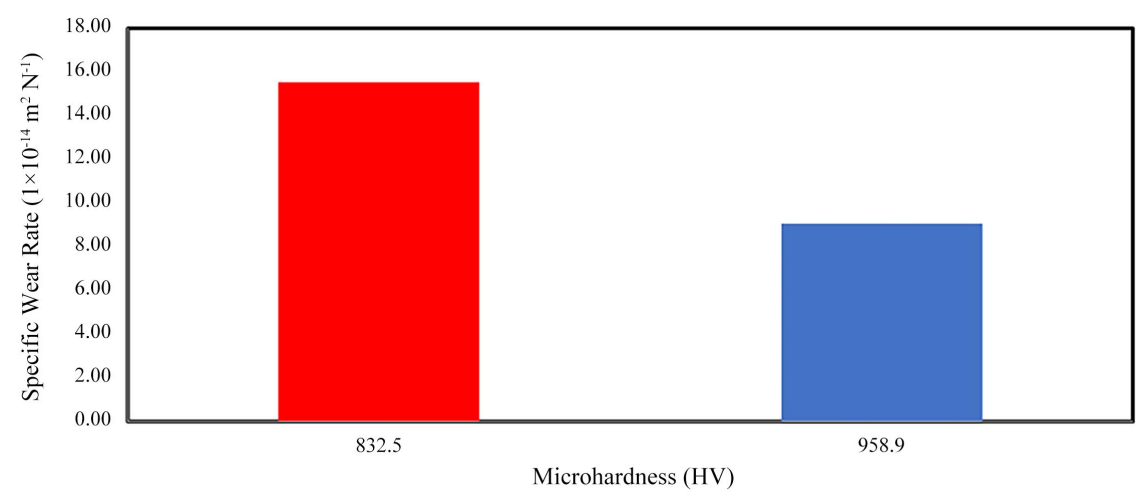

Figure 11. Specific wear rate against microhardness for hardfacing coating cooled in air and water.

\section{Conclusions}

Application of coating by a simple technique like tape casting was successfully used to obtain a hardfacing coating on metal substrate, with equivalent or superior results in mechanical properties than those obtained for welding-based techniques. To obtain the best results, after sintering the cooling of the hardfacing must be made by quenching in water, instead of cooling in air. The samples cooled in air had a coarser microstructure than those cooled in water. Regardless of the cooling rate, the phases that formed after the sintering process are $M_{2} B$, $\mathrm{M}_{7} \mathrm{C}_{3}$, and $\mathrm{M}_{23} \mathrm{C}_{6}$, where $\mathrm{M}$ is $\mathrm{Fe}, \mathrm{Cr}, \mathrm{Mn}$ or a combination of these elements, and a solid solution of FeCr. However, hardfacing pieces cooled in air present hard phases surrounded by a laminar eutectic phase, while the samples cooled in water had these same hard phases surrounded by a skeleton form eutectic phase. There is a significant difference between the microhardness of the two types of eutectic; the laminar eutectic is $445.7 \mathrm{HV}$, and the skeleton eutectic is $887.2 \mathrm{HV}$. Another important result is that by quenching in water, both parts (substrate and coating) increase their wear resistance, thus implying better performance of tools.

The hardfacing coatings present a good metallurgical bond to the substrate, which was evident from the absence of holes in the interphase, and there is evidence of diffusion of elements from the coating to the substrate, thus creating a chemical bond, not only a mechanical bond. Thus, the wear resistance of the hardfacing applied by tape casting technique and cooled in water is equivalent to that obtained by welding-based processes, with the advantage of a simpler process.

\section{Highlights}

A simple process was developed to apply a hardfacing coating on steel substrates by tape casting and sintering.

Cooling rate after sintering is a key factor to maximize mechanical properties of the hardfacing alloy.

The effect of cooling rate after sintering modifies the eutectic phase morphology. 


\section{Conflicts of Interest}

The authors declare no conflicts of interest regarding the publication of this paper.

\section{References}

[1] Yüksel, N. and Şahin, S. (2014) Wear Behavior-Hardness-Microstructure Relation of Fe-Cr-C and Fe-Cr-C-B Based Hardfacing Alloys. Materials \& Design, 58, 491-498. https://doi.org/10.1016/j.matdes.2014.02.032

[2] Venkatesh, B., Striker, K. and Prabhakar, V.S.V. (2015) Wear Characteristics of Hardfacing Alloys: State-of-the-Art. Procedia Materials Science, 10, 527-532. https://doi.org/10.1016/j.mspro.2015.06.002

[3] Mellor, B.G. (2006) Surface Coatings for Protection against Wear. Woodhead Publishing, Abington. https://doi.org/10.1201/9781439823422

[4] Mendez, P.F., Barnes, N., Bell, K., Borle, S.D., Gajapathi, S.S., Guest, S.D., Izadi, H., Gol, A. K. and Wood, G. (2014) Welding Processes for Wear Resistant Overlays. Journal of Manufacturing Processes, 16, 4-25. https://doi.org/10.1016/j.jmapro.2013.06.011

[5] Cheniti, B., Miroud, D., Hvizdoš, P., Balko, J., Sedlák, R., Csanádi, T., Belkessa, B. and Fides, M. (2018) Investigation of WC Decarburization Effect on the Microstructure and Wear Behavior of WC-Ni Hardfacing under Dry and Alkaline Wet Conditions. Materials Chemistry and Physics, 208, 237-247.

https://doi.org/10.1016/j.matchemphys.2018.01.052

[6] Revankar, G.S. (1999) Method for Hardfacing a Metal Surface. U.S. Patent No. $5,879,743$.

[7] ASTM G65 (2000) Standard Test Method for Measuring Abrasion Using the Dry Sand/Rubber Wheel Apparatus. ASTM International, West Conshohocken, PA.

[8] Berns, H. and Fisher, A. (1987) Microstructure of Fe-Cr-C Hardfacing Alloys with Additions of Nb, Ti and, B. Metallography, 20, 401-429. https://doi.org/10.1016/0026-0800(87)90017-6

[9] Lee, K., Nam, D.-H., Lee, S. and Kim, C.P. (2006) Hardness and Wear Resistance of Steel-Based Surface Composites Fabricated with Fe-Based Metamorphic Alloy Powders by High-Energy Electron Beam Irradiation. Materials Science and Engineering: $A, 428,124-134$. https://doi.org/10.1016/j.msea.2006.04.088

[10] Liu, D.H., Liu, R.P., Wei, Y.H., Ma, Y. and Zhu, K. (2013) Microstructure and Wear Properties of Fe-15Cr-2.5Ti-2C-xB wt.\% Hardfacing Alloys. Applied Surface Science, 271, 253-259. https://doi.org/10.1016/j.apsusc.2013.01.169

[11] Sadeghi, F., Najafi, H. and Abbasi, A. (2017) The Effect of Ta Substitution for Nb on the Microstructure and Wear Resistance of an Fe-Cr-C Hardfacing Alloy. Surface and Coatings Technology, 324, 85-91. https://doi.org/10.1016/j.surfcoat.2017.05.067

[12] Yoo, J.W., Lee, S.H., Yoon, C.S. and Kim, S.J. (2006) The Effect of Boron on the Wear Behavior of Iron-Based Hardfacing Alloys for Nuclear Power Plants Valves. Journal of Nuclear Materials, 352, 90-96. https://doi.org/10.1016/j.jnucmat.2006.02.071

[13] Kang, A.S., Singh, G. and Cheema, G.S. (2017) Improving Wear Resistance via Hardfacing of Cultivator Shovel. Materials Today. Proceedings, 4, 7991-7999. https://doi.org/10.1016/j.matpr.2017.07.136

[14] Lai, H.-H., Hsieh, C.-C., Lin, C.-M. and Wu, W. (2014) Effect of Oscillating Tra- 
verse Welding on Microstructure Evolution and Characteristic of Hypoeutectic Hardfacing Alloy. Surface and Coatings Technology, 239, 233-239. https://doi.org/10.1016/j.surfcoat.2013.11.048

[15] Straffelini, G. (2015) Friction and Wear: Methodologies for Design and Control. Springer, Berlin. https://doi.org/10.1007/978-3-319-05894-8

[16] Badisch, E., Kirchgaßner, M., Polak, R. and Franek, F. (2008) The Comparison of Wear Properties of Different Fe-Based Hardfacing Alloys in Four Kinds of Testing Methods. Tribotest, 14, 225-233. https://doi.org/10.1002/tt.61

[17] Coronado, J.J., Rodríguez, S.A. and Sinatora, A. (2013) Effect of Particle Hardness on Mild-Severe Wear Transition of Hard Second Phase Materials. Wear, 301, 82-88. https://doi.org/10.1016/j.wear.2012.12.016

[18] Richardson, R.C.D. (1967) The Wear of Metals by Hard Abrasives. Wear, 10, 291-309. https://doi.org/10.1016/0043-1648(67)90093-2

[19] Richardson, R.C.D. (1968) The Wear of Metals by Relatively Soft Abrasives. Wear, 11, 245-275. https://doi.org/10.1016/0043-1648(68)90175-0

[20] Trevisol, C., Jourani, A. and Bouvier, S. (2017) Effect of Martensite Volume Fraction and Abrasive Particles Size on Friction and Wear Behaviour of a Low Alloy Steel. Tribology International, 113, 411-425.

https://doi.org/10.1016/j.triboint.2016.11.001

[21] Zepon, G., Nascimento, A.R.C., Kasama, A.H., Nogueira, R.P., Kiminami, C.S. Botta, W.J. and Bolfarini, C. (2015) Design of Wear Resistant Boron-Modified Supermartensitic Stainless Steel by Spray Forming Process. Materials \& Design, 83, 214-223. https://doi.org/10.1016/j.matdes.2015.06.020

[22] Peng, S.-G., Song, R.-B., Tan, Z.-D., Cai, C.-H., Guo, K. and Wang, Z.-H. (2016) Abrasive Wear Behaviors of Light-Weight Austenitic Fe-24Mn-7Al-1C Steel and Mn13Cr2 Steel. Journal of Iron and Steel Research, 23, 857-866. https://doi.org/10.1016/S1006-706X(16)30131-5

[23] Zambrano, O.A., Aguilar, Y., Valdés, J., Rodríguez, S.A. and Coronado, J.J. (2016) Effect of Normal Load on Abrasive Wear Resistance and Wear Micromechanisms in FeMnAlC Alloy and Other Austenitic Steels. Wear, 348-349, 61-68.

[24] Vuorinen, E., Ojala, N., Heino, V., Rau, C. and Gahm, C. (2016) Erosive and Abrasive Wear Performance of Carbide Free Bainitic Steels-Comparison of Field and Laboratory Experiments. Tribology International, 98, 108-115. https://doi.org/10.1016/j.triboint.2016.02.015 